\title{
La Violación al Derecho de Libertad en la Detención Administrativa Migratoria: el Caso de las Niñas, Niños y Adolescentes Migrantes en México.
}

\author{
María Auxiliadora Moreno Valenzuela ${ }^{1}$
}

Eduardo Acosta Lobatos ${ }^{2}$

Sumario: I. Introducción II. La detención administrativa migratoria en el marco normativo internacional y nacional. III. La afectación de las niñas, niños y adolescentes por la violación a su derecho a la libertad. IV. Conclusiones

\section{Resumen}

En este trabajo se analiza como las leyes migratorias priorizan la detención administrativa migratoria de las niñas, niños y adolescentes migrantes con motivo del procedimiento administrativo de verificación migratoria y como contraria en todo momento el principio de presunción de libertad, al principio de la excepcionalidad de la detención a la que hace referencia la convención de los Derechos del Hombre. Asimismo se analiza cómo estas leyes no cuentan con un procedimiento especial que priorice evaluar las circunstancias particulares de cada una de las personas migrantes para determinar su detención para su posible retorno o deportación, bajo los principios de necesidad, razonabilidad y proporcionalidad.

Palabras clave: niños y niñas migrantes, procedimiento administrativo

\section{Abstract}

In this paper we analyze how immigration laws prioritize immigration administrative detention of children and adolescent migrants to mark the administrative procedure for migration control and as contrary at all times the principle of presumption of freedom, the principle of the uniqueness of the detention referred to the

\footnotetext{
${ }^{1}$ Investigadora de tiempo completo en el Departamento de Derecho de la Universidad de Sonora.

${ }^{2}$ Egresado de la Licenciatura en Derecho de la Universidad de Sonora
} 
Convention on the Rights of Man. It also discusses how these laws do not have a special procedure to prioritize evaluate the particular circumstances of each of migrants attached to determine his arrest for his possible return or deportation under the principles of necessity, reasonableness and proportionality.

Keywords: migrant children, administrative procedure

\section{Introducción}

La Convención de los Derechos del niño, establece en su artículo 37, inciso b), que ningún niño será privado de su libertad ilegal o arbitrariamente. La detención, el encarcelamiento o la prisión de un niño, se contempla tan solo como medida de último recurso y durante un periodo lo más breve posible y siempre de acuerdo a la ley.

Las Reglas Mínimas para la Administración de Justicia de Menores (Reglas de BEIJING) y en tratándose de niñas, niños y adolescentes en conflicto con la ley penal, establecen que siempre que sea posible, se adoptaran medidas sustitutorias de la prisión preventiva, tales como la supervisión estricta, la custodia permanente, la asignación de un familiar o el traslado a un hogar o una institución educativa, las cuales en todo momento tiene que ser llevado a cabo durante el plazo más breve posible y con respeto irrestricto al debido proceso.

En México aun a pesar de que la Ley Migración no contempla a la detención, en forma expresa, establece la "detección" que no es otra cosa que una detención, ya que para que el agente que "detecta" pueda poner a disposición a una persona, necesariamente tiene que estar en posibilidad material de hacerlo. Esta detención ha sido denunciada por las organizaciones de defensa de las personas migrantes como una violación al derecho de libertad y del debido proceso, en virtud de que es una detención fuera incluso, del propio procedimiento administrativo de verificación migratoria. En la fracción $X X$ del artículo 30 la citada ley, contempla la "presentación" como la medida dictada por el Instituto mediante la cual se acuerda el alojamiento temporal de un extranjero que no acredita su situación migratoria 
para la regularización de su estancia o la asistencia para su retorno. Este alojamiento es forzoso, ya que la o las personas migrantes deberán permanecer alojados (detenidos) hasta la conclusión del procedimiento administrativo de verificación migratoria, es decir constituye una privación de libertad. Esta medida, es aplicada en igual forma para las niñas, niños y adolescentes que viajan sin documentos migratorios, violentando su derecho a la libertad y al debido proceso. En este trabajo se revisaran los alcances de la afectación a estos derechos.

La privación de la libertad (detención) de los niñas, niños y adolescentes migrantes con motivo de procedimiento administrativo de verificación migratoria hecha por el Instituto Nacional de Migración, resulta similar a la de los adultos y los esfuerzos de protección que pudieran generarse desde espacios institucionales o de la sociedad civil, chocan con las inconsistencias que con respecto a estas personas de menor edad, se encuentran contenidas en la Ley de Migración y su Reglamento en donde por una parte se les reconoce como un sector en situación de vulnerabilidad y por la otra se establecen mecanismos que violentan su derechos mas fundamentales como el de la libertad y el debido proceso.

II. La detención administrativa migratoria en el marco normativo internacional y nacional

a) Internacional

La Declaración Americana de los Derechos y Deberes del Hombre establece en su artículo 25 que nadie puede ser privado de su libertad si no en los casos y según las formas establecidas por las leyes preexistentes así como también nadie puede ser detenido por incumplimiento de obligaciones de carácter meramente civil, por lo tanto, todo individuo que haya sido privado de su libertad tiene derecho a que el juez verifique sin demora alguna, la legalidad de la medida y a ser juzgada sin dilación injustificada. En términos específicos el derecho a la libertad personal debe regir el principio de que la privación de libertad es una medida excepcional 
en los casos a aquellos en los que se violente una norma meramente de carácter punitivo.

Así mismo como medida excepcional al principio de libertad, señala la Declaración en cita, que la prisión preventiva será el único medio que permita asegurar los fines del proceso en el que la niña, niños o adolescente participen, garantizando que dichas medidas no sean lesivas y que resultarían ineficaces a los fines del proceso.

En el ámbito migratorio, este mismo documento establece que para poder cumplir con las obligaciones contenidas en el artículo 1 y 25, los Estados miembros deben establecer en sus leyes y sus políticas de migración la presunción de libertad de las personas migrantes mientras están sujetas a los procedimientos migratorios y no partir de la presunción de que es privado de su libertad sin afectos que puedan vincularlo a un proceso punitivo. En este sentido la declaración está señalando que en tanto en materia civil y en materia penal la privación de la libertad tiene que ser tomada como un último recurso privativo de la libertad, estableciendo de esta forma la obligación de las autoridades de sujetarse al principio de la excepcionalidad empezando por la presunción de la libertad de las personas.

La Comisión Interamericana de Derechos Humanos (CIDH) ha señalado que el estándar de excepcionalidad de la privación de libertad, debe tener un carácter más elevado, pues las infracciones migratorias no constitucionalizan una infracción de tipo penal.

De igual forma la Convención Americana de Derechos Humanos establece como criterio rector que la determinación de la detención de una persona migrante sólo es permisible cuando se haya implementado o realizado una valoración especifica que incorpore las características propias de la o las personas migrantes que se encuentren en este supuesto y en especial a las niñas, niños y adolescentes, que arroje la necesidad de la detención mientras se resuelve su situación migratoria. 
Esta práctica se considera que es necesaria para dar cumplimiento legítimo a los intereses del Estado, así como igual para poder regular mediante la comparecencia de personas la determinación de su estatus migratorio y posible deportación. Un Estado puede argumentar -solo en forma excepcional- que las personas migrantes son detenidas por seguridad pública deberá determinarlo mediante una evaluación donde se acredite el grado de riesgo que representa la persona para los intereses del Estado y en dicha evaluación no bastara la existencia de antecedentes penales para sustentarlo, siendo necesario que expliquen "las circunstancias particulares por las cuales se considera ese riesgo. Las razones que sustentan la procedencia de la detención deben ser claramente establecidas en la correspondiente decisión" ${ }^{3 "}$.

\section{b) Nacional}

Durante los últimas décadas México es considerado como país de tránsito para cientos de miles de personas migrantes provenientes de Centroamérica que pretenden llegar hacia los Estados Unidos, esta migración es representada en gran medida por personas migrantes de menor edad como son las niñas, niños y adolescentes. Junto con el aumento de la migración de este sector durante los últimos años, se han implementado políticas públicas orientadas al reforzamiento del control de la verificación migratoria, con énfasis en el retorno a los lugares de origen, así como con prácticas institucionales que priorizan la privación de la libertad por sobre la protección, de las personas migrantes, incluyendo a las niñas, niños y adolescentes migrantes.

El informe denominado "La Ruta del Encierro: situación de las personas en detención en Estaciones migratorias y estancias provisionales" de la Organización Sin Fronteras ${ }^{4}$, documentó que el número de personas migrantes que fueron

\footnotetext{
${ }^{3}$ Comisión Interamericana de Derechos Humanos: (2010). Informe sobre inmigración en estados unidos: detenciones y debido proceso. Fecha de consulta el día 14 de julio de 2015. Disponible http://cidh.org/countryrep/USImmigration.esp/Cap.III.htm\# ftn19

${ }^{4}$ Sin Fronteras (2013). "La Ruta del Encierro: situación de las personas en detención en Estaciones migratorias y estancias provisionales". p. 22.
} 
detenidas por el Instituto Nacional de Migración (INM) y recluidas en las estaciones migratorias en el periodo de enero a diciembre del año 2013 fueron 86,929 de los cuales, 81,394 eran provenientes de Centro América, de este total 72,856 fueron hombres y 14,073 fueron mujeres. La detención de las niñas, niños y adolescentes migrantes se incrementó ya que mientras en el año 2012 fueron detenidos 6,107 en el año 2013 esta cantidad ascendió a 9,893 de los cuales 1,898 estaban entre edades de 0 a 11 años y 7,995 entre los 12 a 17 años.

En México, las personas migrantes son titulares de los Derechos Humanos y sus garantías contenidos en la Constitución Política de los Estados Unidos Mexicanos $^{5}$, sin embargo el artículo 11 relativo al derecho a la libertad de tránsito, limita este derecho para las personas extranjeras, al establecer que éste derecho, quedara subordinado en el ámbito administrativo a las leyes de migración e inmigración. Por su parte el artículo 33 constitucional establece la facultad del ejecutivo de expulsar del territorio nacional a las personas extranjeras, fundamentando las causas en la ley, estableciendo el procedimiento administrativo que se tiene que seguir así como el lugar y el tiempo que tiene que durar la detención.

La detención en el ámbito administrativo migratorio de las niñas, niños y adolescentes migrantes es muy compleja, al darse en la práctica, situaciones de detención generalizada de las niñas, niños y adolescentes al igual que sucede con los adultos, dichas detenciones arbitrarias tienden a justificarse en la situación migratoria irregular de las y los detenidos y en el hecho de que deben permanecer detenidos hasta la conclusión del procedimiento administrativo migratorio el cual tendrá como resultado alguna de las formas de regularización contemplada en la Ley, el retorno asistido o en su caso la deportación a sus lugares de origen.

\footnotetext{
${ }^{5}$ Constitución Política de los Estados Unidos mexicanos. Última reforma publicada DOF 10-072015. Fecha de consulta el día 18 de junio de 2015 . Disponible en http://www.diputados.gob.mx/LeyesBiblio/htm/1.htm
} 
Cuando una persona migrante es "detectada" es decir detenida por su status de irregular, es puesta a disposición ante el Instituto Nacional de Migración lo que implica su traslado a una estación migratoria, en donde se dictará el acuerdo de presentación mediante el cual se formaliza la privación de la libertad y se inicia el procedimiento administrativo de verificación migratoria. Dicho acuerdo deberá emitirse, según el artículo 36 de la Ley de migración un plazo no mayor a 36 horas contadas a partir de que la persona migrante fue puesta a disposición del Instituto Nacional de Migración.

La Ley de Migración establece (artículo 111) que el plazo máximo de detención de las personas migrantes es de 15 días hábiles, plazo en el que se tendrá que resolver su situación migratoria mismo que si bien cierto es legal, también es anticonstitucional al controvertir al artículo 21 párrafo 3 que señala, que el plazo máximo para las detenciones administrativas será de 36 horas las cuales se aplicaran como sanciones por infracciones a los reglamentos gubernativos de los que dispone la normativa nacional, mismas que en todo momento tendrán que integrar garantías de debido proceso y protección judicial.

La misma Ley de Migración ${ }^{6}$ autoriza la ampliación del tiempo de detención al señalar que ésta puede prolongarse de 15 hasta 60 días hábiles, cuando la autoridad migratoria funde y motive mediante mandamiento escrito la imposibilidad de poder llevar a cabo el retorno a los lugares de origen o la deportación de las personas migrantes con su situación migratoria irregular durante los primeros 15 días, sujetos a los supuestos contenidos en el artículo 111 de la Ley de migración, siendo estos los siguientes: que no exista información fehaciente sobre su identidad y/o nacionalidad, o exista dificultad para la obtención de los documentos de identidad y viaje (Fracción I), que los consulados o secciones consulares del

\footnotetext{
${ }^{6}$ Ley de migración. Ultima reforma publicada 30-10-2014. Publicada en el Diario Oficial de la Federación (DOF): fecha de consulta el día 18 de octubre de 2014 http://www.diputados.gob.mx/LeyesBiblio/pdf/LMigra_301014.pdf.
} 
país de origen o residencia requieran mayor tiempo para la expedición de los documentos de identidad y viaje (Fracción II), que exista impedimento para su tránsito por terceros países u obstáculo para establecer el itinerario de viaje al destino final (Fracción III), y por último que exista enfermedad o discapacidad física o mental médicamente acreditada que imposibilite viajar al migrante presentado (Fracción IV).

Dentro de los supuestos mencionados en el párrafo que antecede, la Ley de Migración establece que las personas migrantes que están detenidas, necesariamente tienen que ser notificadas a los tres días hábiles siguientes a partir del día siguiente hábil al termino de finalización de los 15 días en el que el Instituto no puedo retórnalos o deportarlos a los lugares de origen por los supuestos mocionados en el artículo 111 de la ley, sin embargo no se establece razón justificada por la que las niñas, niños y adolescentes migrantes se vean afectadas y al mismo tiempo violentadas al derecho de la seguridad jurídica contenida en el numeral 16 Constitucional y el de certidumbre jurídica por el periodo previo a los tres días que permanecen detenidos en las estaciones migratorias a disposición del Instituto Nacional de Migración.

En la práctica esta detención administrativa y sus supuestos de prolongación, resultan violatorias del derecho a la libertad y del derecho al debido proceso de las personas migrantes en general y de las personas de menor edad en particular, en tanto se les sujeta a un procedimiento administrativo penal -que contempla la privación de la libertad- que generalmente se extiende más allá de la privación de libertad, que por detenciones administrativas contempla el mencionado artículo 21 Constitucional, pero sin incorporar las garantías que el procedimiento penal establece para en el caso de que una persona sea molestada en su esfera jurídica y detenida.

La elección de un medio de defensa por aquellas personas migrantes -que deciden ejercer acción legal por la violación a algunos de los Derechos contenidos 
en la Constitución, las leyes respectivas y los tratados internacionales- esta detención puede entonces, prolongarse indefinidamente, situación que obra como elemento disuasivo para que las personas migrantes opten por demandar por las violaciones cometidas en su contra. Lo anterior es aún mas grave, si consideramos que la misma ley migratoria les limita la posibilidad de acceder a la procuración e impartición de justicia al autorizar -en el caso de las personas con status irregular- a la autoridad migratoria para que en lugar de ponerlas a disposición de la autoridad jurisdiccional, las interne en calidad de detenidas en la o las estaciones migratorias correspondientes.

En el caso de las niñas, niños y adolescentes migrantes a pesar de que la misma Ley de Migración y su Reglamento, les reconocen la situación de vulnerabilidad que les deviene no sólo por ser migrantes y por estar en tránsito, sino principalmente por su minoría de edad, no establecen garantías específicas para evitar que permanezcan privadas de la libertad en y durante el desahogo del procedimiento de verificación migratoria, violando de esta manera su derecho de libertad y de acceso al debido proceso, entre otras.

[...]Respecto del tiempo de permanencia en la estación migratoria, 173 personas en Iztapalapa, 60 en Tenosique y 24 en Villahermosa manifestaron haber estado detenidas hasta 15 días hábiles; por su parte, 46 personas en Iztapalapa, cuatro en Tenosique y tres en Villahermosa, llevaban entre 16 y 60 días hábiles detenidas; finalmente, 18 personas en Iztapalapa y una en Villahermosa llevaban más tiempo del máximo permitido en la Ley de Migración: 60 días hábiles. Adicional a lo anterior, 53.65 por ciento de las personas encuestadas en Iztapalapa refirieron conocer personas que se encontraban en la estación migratoria detenidas por más de un mes; lo mismo sucedió con 25 por ciento 
de gente entrevistada en Tenosique y 63.88 por ciento en Villahermosa, Tabasco ${ }^{7}$.

En el caso de las personas migrantes y en particular a las niñas, niños y adolescentes que se les sujeta al procedimiento administrativo de verificación migratoria, la detención obligada en México, es totalmente contraria con el: 1) el principio de presunción de libertad del que se ha venido haciendo mención en las declaraciones en cita con indistinción del carácter o estatus migratorio en el que se encuentren las personas migrantes, 2) el principio de excepcionalidad de la detención, y 3) la obligación de que el Estado Mexicanos establezca un procedimiento que le permita evaluar las circunstancias particulares de cada una de las personas migrantes apegadas a los principios de necesidad, razonabilidad y proporcionalidad, de forma previa a la privación de la libertad.

Aunque México no sanciona penalmente el hecho de que una persona migrante ingrese o permanezca de manera irregular en el país,, la detención de carácter legal y obligatorio del que se hace valer el Instituto Nacional de Migración (INM) tiene en la práctica, el efecto de convertir una violación administrativa -la introducción al país sin documentos- en un delito, al someterla a un procedimiento que contempla la privación de la libertad -como la contemplada en la legislación penal- sin contemplar las protecciones que dicha ley penal contempla para cuando una persona se encuentra en este supuesto. De esta forma las personas migrantes, incluyendo las niñas, niños y adolescentes son criminalizados y posteriormente sancionados con la pérdida de la libertad violentándoseles las garantías del proceso en aras del cumplimiento del debido procedimiento administrativo al que alude el artículo 70 de la Ley de Migración. Sumándose a esto, la violación que implica el excesivo tiempo que permanecen puestos a disposición del Instituto, agravándose esta situación, cuando han sido víctimas de

\footnotetext{
${ }^{7}$ Sin Fronteras (2013). "Ser migrante no me hace delincuente: Situación de las personas en detención en las estaciones migratorias de Iztapalapa, Distrito Federal, Tenosique, Villahermosa, Tabasco", p. 35.
} 
delitos y se les impide -administrativamente hablando- acceder a la procuración y administración de justicia con la debida diligencia y aplicando el principio del interés superior de la niñez.

III. La afectación de las niñas, niños y adolescentes por la violación a su derecho a la libertad

La privación de la libertad de las niñas, niños y adolescentes migrantes en las estaciones migratorias tiene un impacto directo con el aspecto psicoemocional, mismo que se agrava por el uso de cuartos de castigos. En estos casos se han documentado la existencia de tortura psicológica que se les infringe por parte de las autoridades migratorias, la cual es producto de la incertidumbre de no saber el tiempo de permanencia en dicha estación así como por el desconocimiento del procedimiento administrativo al que se sujetaran de manera obligatoria así como por "la desorientación y el lenguaje coercitivo de algunos custodios o del personal del Instituto Nacional de Migración que parecen orientados a generar miedo y a evitar nuevos intentos de migración con el cual, en algunos casos, logran debilitar su voluntad"8.

Así mismo existe una afectación psicológica producto del encierro de las personas migrantes que esta relacionada con la estructura de las habitaciones en las que se alojan obligadamente, que tienen dimensiones muy reducidas, se ha documentado una ausencia de actividades recreativas, dificultad para realizar llamadas telefónicas, incertidumbre sobre el tiempo en que permanecerán en esos sitios, todo lo cual indudablemente se constituye además, en una violación de sus derechos humanos.

\footnotetext{
${ }^{8}$ Sin fronteras (2013). La ruta del encierro: Situación de las personas en detención en estaciones migratorias y estancias provisionales. P.53.
} 
En una encuesta realizada por Sin Fronteras (2013) a 276 personas migrantes que se encontraban en la estación migratoria en Iztapalapa en año 2012, éstas refirieron que durante su estancia en ese lugar, la mayoría de ellos fueron ofendidos verbalmente por parte de los custodios que se encontraban al cuidado de la estaciones, así como la realización de prácticas coercitivas que ante una falta o un comportamiento considerado inapropiado de parte de las personas migrantes, éstas eran encerradas en áreas que son destinadas para las personas de preferencia sexual diferente o para los enfermos mentales.

Sobre las medidas de coerción que se ejercen dentro de la estación migratoria, las personas alojadas contaron que en el área de varones existen tres cuartos pequeños que no están ocupados y están destinados a homosexuales y enfermos mentales, pero que si alguien comete alguna falta o tiene mal comportamiento, es encerrado en uno de esos cuartos por varias horas ${ }^{9}$.

En cuanto a las niñas, niños y adolescentes, la mayoría de los encuestados manifestaron el aumento de los cuartos de castigo los cuales están especialmente destinados para ellos, y a donde eran enviados a que reflexionaran por el comportamiento que habían tenido durante la estancia en dichas estaciones, así mismos evidenciaron el abuso de autoridad que se vive en estos lugares en incluso hasta por el director.

[...]“En uno de los grupos de adolescentes un joven preguntó a una de las facilitadoras - ¿Oiga, y está permitido que a uno le peguen aquí?, entonces detalló que uno de sus compañeros fue enviado al cuarto de castigo por no obedecer a uno de los guardias; éste quiso intimidarlo haciendo la finta de que le iba a

\footnotetext{
${ }^{9}$ Sin Fronteras (2013). "Ser migrante no me hace delincuente: Situación de las personas en detención en las estaciones migratorias de Iztapalapa, Distrito Federal, Tenosique, Villahermosa, Tabasco", p. 39.
} 
pegar, el joven no se dejó y cuenta "haberse puesto en guardia y retar también al agente del INM" Ante esto, el director de la estación migratoria apareció personalmente para amenazar al joven con llevarlo al tutelar de menores por delincuente y le dijo que no volvería a su país en un buen rato pues ahí si era una cárcel. El chico se retrajo y fue enviado al cuarto de castigo por tres días, relató otro de ellos, quien fue testigo que al llevárselo lo golpearon. Luego el mismo agredido complementó: "Me ponían ahí parado, con los brazos levantados contra la pared y no me dejaba que los bajara porque decían era de castigo". Otro de ellos contó que a él, de igual forma, lo amenazaron con la historia del tutelar y con llevarlo al cuarto de castigo ${ }^{10}$

A estas problemáticas resultan importante agregar las de las condiciones estructurales en las que se encuentran las estaciones migratorias, la alimentación que no es la adecuada, una falta de iluminación y ventilación, ausencia de utensilios necesarios para la higiene personal, adecuaciones de servicios sanitarios, ropa y camas en mal estado y la constante sobrepoblación y alojamiento.

\section{Conclusiones}

En el caso de las niñas, niños y adolescentes que se les sujeta al procedimiento administrativo de verificación migratoria, la detención obligada en México es totalmente contraria con el principio de presunción de libertad a la que hace referencia la Convención de los Derechos del Hombre, al principio de excepcionalidad de la detención siendo esta como una medida de último recurso, así como la obligación que tiene Estado Mexicano de establecer un procedimiento que le permita evaluar las circunstancias particulares de cada una de las personas

\footnotetext{
${ }^{10}$ Ibídem.
} 
migrantes apegadas para determinar su detención para su posible retorno o deportación, bajo los principios de necesidad, razonabilidad y proporcionalidad.

Asimismo, en la práctica las políticas migratorias carecen de métodos alternativos a la detención, así como de criterios claros para su procedencia o bien se establecen procedimientos que limitan el ejercicio para su acceso. En este sentido

el esquema de políticas públicas con orientación migratoria no responde a las realidades migratorias y por lo tanto se ven reflejadas en las violaciones reiteradas de los derechos humanos de las personas migrantes de menor edad, ante la ausencia de programas, prácticas, medidas y mecanismos para una efectiva aplicación de medidas alternativas a la detención.

\section{Bibliografía}

Comisión Interamericana de Derechos Humanos (CIDH: 2012), Informe No. 86/09, Caso 12.553 (Fondo) Jorge, José y Dante Peirano Basso (República Oriental del Uruguay) del 6 de agosto de 2009, párr. 100.

Convención sobre los derechos del niño.

Aprobado por el Senado de la República el 19 de junio de 1990, Entró en vigor en el ámbito internacional el 2 de septiembre de 1990. Fecha de consulta el día 19 de julio 2015.

Disponible en: http://www.cndh.org.mx/sites/all/fuentes/documentos/Programas/Discapacid ad/Conv_DNi\%C3\%B10.pdf

Convencion Americana Sobre Derechos Humanos (Pacto San Jose).

Aprobada en la fecha: 22 de noviembre de 1969,por: La conferencia Especializada Interamericana Sobre Derechos Humanos. Publicada en el D. O. F: 9 / I, 7 / V / de 1981 y 17 / I del 2002, entrada en vigor para México, 24 de marzo de 1981. Disponible en:

\section{http://www.pgjdf.gob.mx/temas/4-6-1/fuentes/3-B-4.pdf}


Constitución Politica de los Estados Unidos Mexicanos. Disponible en: http://www.dof.gob.mx/constitucion/septiembre_2014_constitucion.pdf

Corte Interamericana de Derechos Humanos (2010). Informe sobre inmigracion en Estados Unidos: Deteciones y debido proceso

Declaración Universal de Derechos Humanos. Adopción: Asamblea General de la ONU Resolución 217 A (III), 10 de diciembre de 1948. Disponible en: http://www.ordenjuridico.gob.mx/TratInt/Derechos\%20Humanos/INST\%200 0.pdf

Mexico, Reglamento de la Ley de migracion.

Publicada en el Diario Oficial de la Federacion (DOF): 28/09/2012. Fecha de consulta el dia 18 de junio de 2015. Disponible en:

http://www.dof.gob. $m x /$ nota_detalle.php?codigo=5270615\&fecha=28/09/201 $\underline{2}$

Mexico, Ley de Migracion.

publicada en el Diario Oficial de la Federacion (DOF): fecha de consulta el dia 20 de junio de 2015.

http://www.inm.gob.mx/static/marco juridico/pdf/Ley_de_Migracion_y_Regla mento.pdf

Rafael Ferrer-Mazorray otros (Estados Unidos), Informe No. 51/01 (fondo), Caso 9903, párr. 219 (4 de abril de 2001), disponible en http://www.cidh.oas.org/annualrep/2000sp/Capituloll//Fondo/EEUU9903.htm

Reglas mínimas de las naciones unidas para la administración de la justicia de menores "reglas de beijing", Adopción: Asamblea General de la ONU, Resolución 40/33, 29 de noviembre de 1985, fecha de consulta el día 27 de julio de 2015. Tomado de http://www.ordenjuridico.gob.mx/TratInt/Derechos\%20Humanos/OTROS\%2 018.pdf

Sin fronteras (2013). "Ser Migrante no me hace delincuente" situación de las personas en detención en las estaciones migratorias de Iztapalapa, Distrito Federal, Tenosique, Villahermosa y Tabasco 2011- 2012. Fecha de consulta el día 13 de junio de 2015. Disponible en: 
Sin fronteras (2013). La ruta del encierro: Situación de las personas en detención en estaciones migratorias y estancias provisionales. Fecha de consulta el día 1 de mayo de 2015 Disponible en http://sinfronteras.org.mx/attachments/informe-2014.pdf 